\title{
SEMMUDIK : Selamat Mudik Menggunakan Helm Berbasis Internet Of Things (Iot)
}

\author{
Fika Trisnawati' ${ }^{1)}$, Purwono Prasetyawan, M.T. ${ }^{2)}$
}

\author{
1) 2) S1 Teknik Elektro, Universitas Teknokrat Indonesia \\ Jl. ZA. Pagar Alam No.9-11, Labuhan ratu, Kec Kedaton, \\ Bandar Lampung, Lampung 35132 \\ Email:fikat18@gmail.com ${ }^{1)}$, purwono.prasetyawan@teknokrat.ac.id ${ }^{2)}$
}

\begin{abstract}
Abstrak
Berkendara motor merupakan transportasi alternatif yang murah dan lebih cepat sampai tujuan. Alternatif ini sering dipilih oleh pemudik. Keselamatan perjalanan adalah hal yang diutamakan, salah satunya pengendara wajib menggunakan helm. Pada kesempatan ini penulis mengambil tema transportasi: "Selamat mudik menggunakan helm berbasis Internet of Things (IoT)".

Helm ini mempunyai fitur diantaranya adalah mampu berinteraksi antar pengendara satu dengan lainnya dalam cakupan lokasi yang dipresentasikan dengan google maps. Bila helm tidak digunakan dengan benar, maka mesin motor tidak bisa dihidupkan. Fitur lainnya adalah jika pengendara mengantuk helm ini memberikan peringatan untuk istirahat terlebih dahulu dan bila pengendara jatuh helm ini bisa berkomunikasi dengan Posko Mudik terdekat untuk mendapatkan pertolongan segera, serta menunjukkan lokasi kejadian.

Sistem IoT dengan objek helm yang saling terkoneksi dengan helm pengendara lainnya melalui media internet dengan interface pada device smartphone Android ini kami beri nama SEMMUDIK, tujuan sistem ini semoga para pemudik dapat selamat sampai tujuan.
\end{abstract}

Kata kunci: Mudik, Pemudik, Posko Mudik, Helm, IoT, Andorid

\section{Pendahuluan}

Era revolusi industry 4.0 banyak kemudahan teknologi yang akan ditawarkan ke masyarakat dunia, salah satunya pada teknologi Internet of Things (IoT) yang bisa di gunakan masyarakat untuk memudahkan kegiatan seperti penulis buat SEMMUDIK (Selamat Mudik Dengan Helm Berbasis IoT).

Helm merupakan benda yang digunakan di kepala yang pasti berfungsi sebagai pelindung kepala jika sewaktu-waktu pengguna mengalami benturan untuk menghindari terjadinya benturan langsung dengan subjek benturannya. Helm biasa digunakan oleh pengendara sepeda motor sebagai sefty, pekerja proyek bangunan, pekerja PLN, dan lain sebagainya. Tentu saja helm sangat penting fungsinya selain untuk melindungi kepala jika sewaktu-waktu mengalami kecelakaan, kajatuhan matrial dari atas dan lain sebagainya. Helm juga mempunyai berbagai jenis dimana setiap jenisnya memiliki kualitas masing-masing dan bentuknya bermacam-macam berikut jenis helm yang digunakan pengendara sepeda motor, Shorty Helmet, Open Face Helmet (Half Face Helmet), Modular Helmet, Full Face Helmet, dan Flip-Up Helmet. Dari 5 jenis helem tersebut memilikin tingkat kekuatan masing tergantung jenis helmnya.

SEMMUDIK (Selamat Mudik Dengan Helm
Berbasis $I o T$ ) adalah sebuah program untuk pengendara sepeda motor dimana helm yang terkoneksi dengan smartphone melalui internet. Program ini bertujuan pengendara selamat pada waktu pulang kampung ataupun pas mudik, program SEMMUDIK ini bertujuan untuk mengirim data ke tempat-tempat yang terkoneksi dengan alat contohnya pos-pos mudik yang ada di daerah-daerah yang diindonesia jika pengendara sepeda motor mengalami kecelakaan system ini langsung mengirim data ke pos yang sudah terkoneksi dengan alat.

Dengan program yang di buat oleh penulis yaitu untuk mengantisipasi pengendara yang mengalami ngantuk pada saat berkendara, program akan memberi peringatan kepada pengendara dengan notifikasi atau suara sebagai peringatan. Helm ini juga terhubung dengan sepeda motor, saat pengendara ingin menggunkan sepeda motor otomatis pengendara akan memakai helm SEMMUDIK karena terdapat fitur yaitu helm dan sepeda motor saling terhubung, dimana helm tersebut sebagai saklar/kontak awal jika ingin menggunakan sepeda motor, dimana prototype tersebut telah terpasang pada helm dan tertanam sbeuah program system yang terintegrasi yaitu, program SEMMUDIK.

Teknologi Internet of Things yang digunakan dalam tema transportasi ini yaitu digunakan untuk keamanan, penolong, sebagai kontak motor, dan sebagai interaksi pengedara yang mengalami kecelakaan dan 
mengirim pesan darurat ke kerabat dekat ataupun kepospos mudik dengan mengirim pesan atau data. Teknologi internet saat ini banyak sekali digunakan untuk sebagai pengonektivitas dengan program yang manusia buat dengan mengandalkan fitur-fitur yang di hubungkan dengan internet penulis ingin mengembangkan fitur-fitur tersebut. Sistem IoT dengan objek helm yang saling terkoneksi dengan helm pengendara lainnya melalui media internet dengan interface pada device smartphone Android ini sangatlah bagus untuk membantu pengendara sepeda motor sebagai keamanan yang terpasang dengan teknologi cerdas di era revolisi 4.0 ini.

Saat ini proses integrasi data sudah dipermudah dengan adalah teknologi internet. APJII atau Asosiasi Penyelenggara Jasa Internet Indonesia mengumumkan hasil dari survei data statistik pengguna internet Indonesia pada tahun 2016 sejumlah 132,7 juta penguna atau $51,5 \%$ dari total penduduk Indonesia sebesar 256,2 juta jiwa. Pulau Jawa menjadi pengguna internet dengan jumlah 86.339.350 user atau sekitar 65\% dari total seluruh penggunan Internet di Indonesia. Terjadi kenaikaan jika dibandingkan pengguna Internet Indonesia pada tahun 2014 sebesar 88,1 juta user dan 2016 sebesar 44,6 juta user dalam waktu 2.

Internet of Things (IoT) merupakan suatu konsep dimana suatu objek yang memiliki kemampuan untuk mengirimkan data melalui jaringan tanpa memerlukan interaksi manusia ke manusia atau manusia ke computer.

Untuk membantu terwijudnya SEMMUDIK dalam penyedian helm cerdas ini maka dibuatlah inovasi baru dibidang transportasi kendaraan sepeda motor untuk membantu keamannanya kepala pengendara supaya lebih aman lagi dan menjaga pengendara tidak ngantuk. Teknologi ini diharapkan mampu menjadi inovasi dan strategi para pengendara sepeda motor pada saat melakukan mudik ataupun pada saat perjalanan jarak jauh atau jarak jauh dengan teknologi ini mengharapkan mengurangi kecelakan di Indonesia khususnya di jalur transportasi dan mewujudkan teknologi SEMMUDIK 2030.

\section{Landasan Teori}

Mudik adalah kegiatan yang biasa dilakukan oleh para perantau/pekerja migran untuk kembali ke kampung halaman masing-masing. Mudik di Indonesia sudah menjadi tradisi tahunan yang dilaksanakan menjelang hari raya besar keagamaan seperti lebaran dan natal. Karena pada kesempatan itu mereka dapat berkumpul dengan sanak saudara. Mayoritas transportasi yang biasanya digunakan saat mudik antara lain : Pengendara sepeda motor hal ini dikarnakan pemudik menggunakan sepeda motor karena cepat dan hemat saat perjalanan, di samping itu satiap pengendara sepeda motor harus menggunakan Helm supaya tidak beresiko pada kecelakaan.

\subsection{Helm SNI}

Para pemudik saat menggunakan Helm SNI sudah teratur pada suatu lintasan jalan raya ini dibuktikan pada polisi setempat, tetapi dalam menggunakan Helm SNI ini masyarakat perlu pembaruan pada Helm tersebut contoh yang penulis buat yaitu : Helm yang berbasis dengan Iot atau (SEMMUDIK) Helm ini yang sudah berbasis Iot dapat membantu pengendaranya seperti mempunyai beberapa fitur di antaranya mampu berinteraksi pada pengendara yang lainya dalam cakupan lokasi yang diperesentasikan oleh google maps. Helm canggih ini pun bisa memaksa pengendara untuk menggunakan sepeda motornya, bila tidak motor tersebut mesin motor tidak bias dihidupkan.

Pada system yang tertanam pada SEMMUDIK tersebut dapat memudahkan bagi pengendara sepeda motor dan meningkatkan keselamatanlah yang terpenting bagi setiap pengendara sepeda motor.

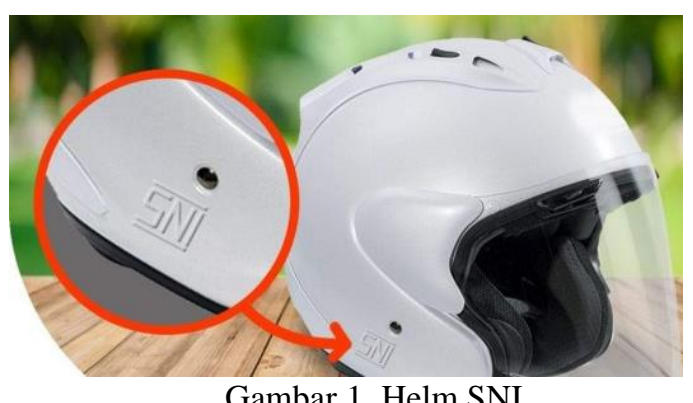

Kenyamanan dan keselamatan pengguna sepeda motor saat menggunakan Helm Kenyamanan sangatlah berarti bagi pemudik pengendara sepeda motor hal ini sudah dibuktikan pada masyarakat diseluruh Indonesia saat menjelang mudik atau lebaran tiba, sesuai dengan kenyamanan yang diinginkan oleh masyarakat penulis sudah meneliti untuk kenyamanan saat berkendara sepeda motor dengan helm yang sudah berteknologi IoT, kenyamanan pada helem yang sudah berbsis IoT ini, yaitu helm pintar tersebut memberitahukan si pengendara apabila pengendara sepeda motor tersebut mengantuk saat perjalanan,apabila pemudik mengalami kecelakaan helm tersebut memberitahukan kepada posko keselamatan terdekat memberitahukan lokasi kejadiannya.

\subsection{Pemudik}

Pemudik adalah salah satu tradisi tahunan yang dilakukan seluruh masyarakat Indonesia sebagai suatu kegiatan perantau /pekerja untuk kembali kekampung halaman tercinta, disamping itu para pemudik mayoritas nya menggunakan tranformasi kendaraan bermotor. Berikut merupakan gambaran pemudik yang akan menuju kampung halaman. 


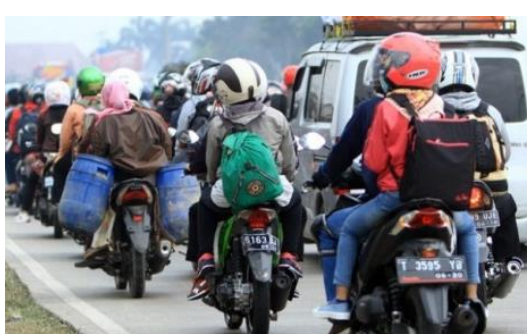

Gambar 2. Situasi Mudik

\subsection{Posko pemudik}

Kegiatan posko mudik yaitu tempat suatu sarana kemanusian yang dimana posko pemudik yang tujuan nya adalah membantu pemudik saat megalami suatu kecelakaan di jalan lalu lintas, untuk beristirahat bahkan untuk menanyakan rute yang paling tepat menuju tempat tujuan mudik.

Pada posko pemudik diindonesia yang masih belum mempunyai teknologi canggih untuk mengetahui dimana saat korban mengalami kecelakan, pada kali ini penulis sudah meneliti bagaimana seorang pemudik yang mengalami kecelakaan yang tidak di dekat area pos pemudiknya, pada SEMMUDIK inilah yang penulis karang bagaimana saat pengendara sepeda motor mengalami kecelakan jauh di posko pemudik, pada system SEMMUDIK ini memberitahukan apabila seorang pengendara sepeda motor mengalami kecelakaan helm yang sudah berbasis IoT ini akan memberitahukan kepada tempat posko pemudik secara otomatis melalui internet dengan interface pada device smarphone Android.

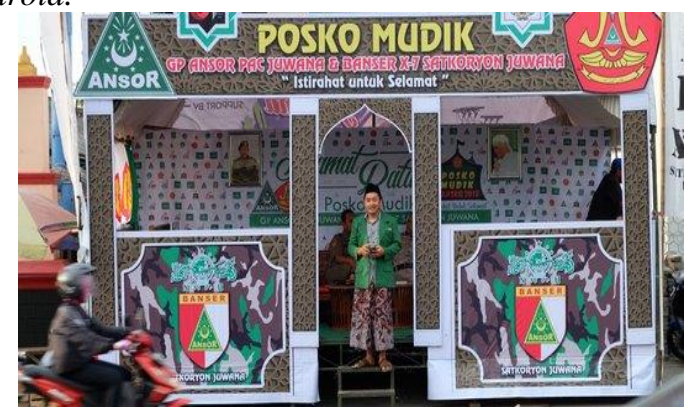

Gambar 3. Posko mudik lebaran

\subsection{Internet of Things}

Kevin Ashton pada tahun 1999 adalah tokoh yang pertama kali memperkenalkan Internet of Things (IoT). Meskipun sudah dikenalkan sejak 15 tahun yang lalu, sampai saat ini belum ada konsensus global mengenai definisi IoT. Konsep IoT secara umum diartikan sebagai suatu kemampuan untuk menghubungkan benda ataupun objek cerdas sehingga memungkinkannya untuk berinteraksi dengan objek lain, lingkungan bahkan peralatan komputasi cerdas lainnya melalui jaringan internet. IoT telah mulai diaplikasikan dalam berbagai bentuk pada banyak aspek kehidupan manusia. Bahkan CISCO telah menargetkan pada tahun 2020 akan ada 50 miliar objek yang terhubung dengan internet.

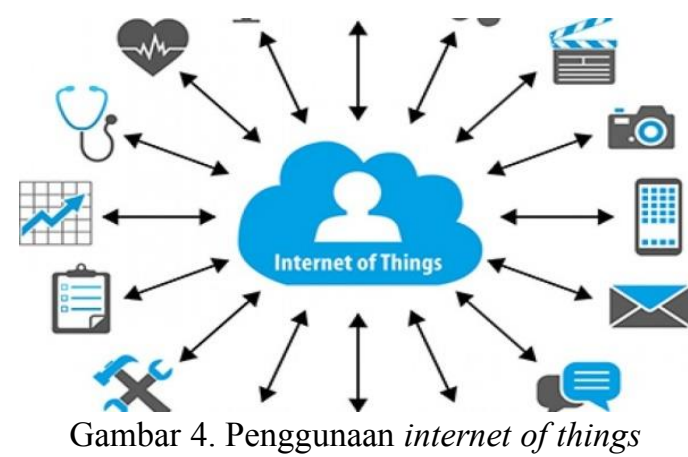

Dewasa ini untuk menganalisa data dalam jumlah yang besar bukan lagi menjadi hal spektakuler. Big Data Analyst dapat dipekerjakan atau dilatih untuk memahami pola dalam data oleh setiap organisasi. Pada 2016, seluruh tindakan bisnis yang diambil akan didasarkan pada data. Algoritma sendiri yang akan menentukan tindakan apa yang harus diambil dengan mengadopsi Artificial Intelligence (AI). Beberapa penelitian yang membahas Internet of Things sudah banyak diterapkan pada berbagai bidang keilmuan dan industri, seperti pada bidang kesehatan, informatika, geografis dan beberapa bidang ilmu lain.

Sistem monitoring kesehatan pasien dengan menggunakan wireless sensor yang dipasangkan pada tubuh pasien kemudian beberapa hal dipantau seperti psikologi pasien, tekanan darah dan detak jantung. Seluruh kegiatan itu dilakukan melalui peralatan yang terhubung ke internet dan tentu dengan memperhatikan kerahasiaan data pasien. Selain itu penerapan Internet of Things juga diterapkan pada kegiatan konsultasi pasien, menggunakan jaringan WLAN dan internet sehingga proses konsultasi dapat terjadi secara remote antara pasien dan dokter.

Pada saat itulah IoT (intenet of Things) menggalami perkembangan dari tahun ke tahunya, sebuah teknologi iot ini bisa dapat memudahkan aktifitas manusia dengan teknologi yang sangat canggih dan spektakuler.

\subsection{Android}

Android merupaka sistem operasi yang berbasis linux dengan menerapkan manipulasi secara langsung sehingga ponsel dapat merespon input sentuhan seperti gesekan, cubit, ketukan, menekan dan lain-lain. Dan karena ia bersifat open source, maka pihak pengembang aplikasi dan pabrikan dapat memperluas fungsionalitasnya ke batas-batas maksimal.

Android di dunia sudah sangat terlebarluaskan perkembangan dan sangat di butuhkan oleh manusia dalam kehidupan sehari - harinya, bagaimana tidak android merupakan system yang sangat cepat dalam teknologi 4.0.

\section{METODE PENELITIAN}

\subsection{Rancangan penelitian}


Penulis memilih menggunakan metode penelitian secara kuantitatif karena metode ini adalah yang disebut metode pengukuran, metode kuatitatif ini mengutamakan data - data yang berupa angka sehingga pada gejala yang di teliti dan dapat diukur dengan skala,indeks dan tabel.

Pada pendekatan ini metode yang akan di teliti adalah sebuah system yang berbasis Internet of Things yang dimana penulis membuat sebuah system yang sudah tercontrol melalui android dan internet secara otomatis, dalam pendekatan ini penulis dapat menggunakan angka dan system jaringan yang sudah dapat tercontrol melalui internet yang datanya disertai oleh, system kerja SEMMUDIK, grafik pada sinyal, gambaran tampilan dan yang lainya untuk mendukung penelitian ini.

\subsection{Teknik pengumpulan data}

Teknik yang digunakan dalam proses mengumpulkan data pada penelitian ini yaitu sebagai berikut :

\subsubsection{Teknik wawancara}

Pada teknik wawancara ini dapat melengkapi data dan survei yang diperlukan untuk memberikan solusi kepada penulis untuk merancang sebuah helm (SEMMUDIK) yang sudah berbasis IoT. Wawancara yang dilakukan oleh penulis ini agar bisa mendapatkan solusi untuk mencari data pengendara sepeda motor yang masih tidak nyaman saat menggunakan helm biasa atau yang belum menggunakan system teknologi IoT hal ini dikarnakan agar penulis dapat membuat rancangan dengan sebaik mungkin.

\subsubsection{Teknik observasi}

Pada teknik observasi penulis akan melakukan sebuah pengamatan untuk SEMMUDIK pada saat menjelang lebaran, yang dimana penulis akan mencari penyebab ketidaknyamanan menggunakan helm SNI sehingga penulis bisa dapat merancang sebuah helm yang cerdas dan nyaman saat digunakan.

\subsubsection{Study pustaka}

Metode studi pustaka yang penulis lakukan yaitu untuk menunjang metode-metode yang telah Penulis lakukan. Pengumpulan yang berupa informisi dan datadata yang sudah penulis lakukan terkait dengan mencari referensi, jurnal-jurnal dan informasi pada data-data yang penulis lakukan.

\section{PEMBAHASAN}

Berdasarkan rumusan masalah dan tujuan diatas, penulis menyimpulkan beberapa poin penting tentang apa yang sedang penulis rancang untuk kenyamanan dan keselamatan pengendara sepeda motor yang sudah terhubung dengan internet dan google maps dari penerapan teknologi Internet Of Things.

\section{Cara kerja system Monitoring Helm pada android :}

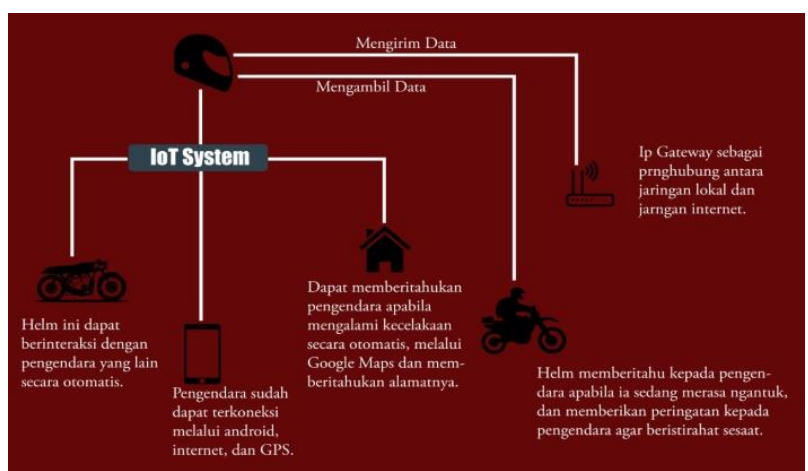

Gambar 5. Rancangan SEMMUDIK yang berbasis IOT

Pada SEMMUDIK yang penulis buat ini agar dapat memonitoring sebuah smartphone android secara otomatis, system kerja helm SEMMUDIK yaitu dengan memanfaatkan sensor pendeteksi jaringan wireless yang dihubungkan dengan mikro kontroler, output dari sensor smartphone android yang berupa sinyal analog ini yang nantinya akan diproses dengan mikrokontroler sehingga menghasilkan data berupa maps yang bertujuan agar pengendara sepeda motor tetap tercontrol pada pengguna helm SEMMUDIK lainya.

Kemudian data tersebut dikirimkan melalui media internet menuju penyimpanan data secara online, hal ini di karnakan apabila pemudik mengalami kecelakaan di jalan, sebuah helm cerdas yang sudah berbasis Internet of Things ini akan secara otomatis memberitahukan kepada posko mudik terdekat dan memberitahukan lokasi kejadianya melalui smartphone android agar secepatnya pertolongan medis kepada pemudik tersebut.

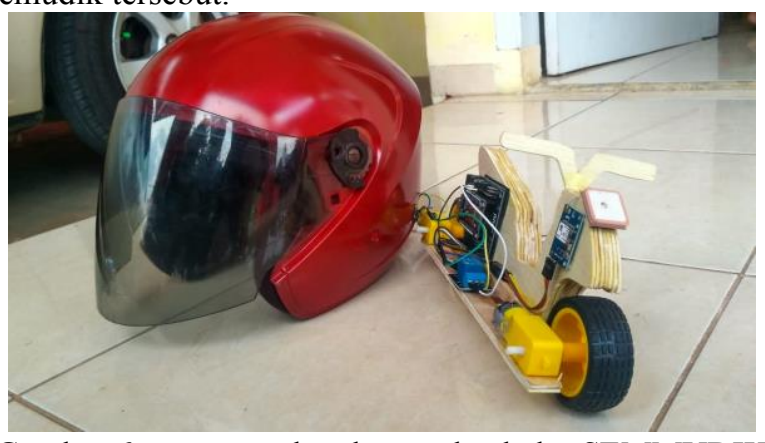

Gambar 6. prototype kendaraan dan helm SEMMUDIK

\section{PENUTUP}

\subsection{Kesimpulan}

Dari bentuk helm yang belum canggih/cerdas penulis ingin membuat helm yang lebih cerdas dengan mewujudkan sistem Internet Of Things dengan keamanan yang lebih dan memberikan informasi terhadap penjaga pos mudik. Dengan demikian masyarakat harus sadar dengan keselamatan terhadap dirinya jika ingin brkendara sepeda motor harus menggunakan helm yang berbasis Internet Of Things (IoT) ini untuk menghindari ngantuk dan sebagainya. Dengan itu penulis membuat alat dengan alat yang sudah tersedia di toko-toko elektronik untuk memudahkan dalam pengerjaannya. 
Untuk revolusi teknologi 4.0 saat ini banayak sekali yang akan di keluarkan ide-ide kreatif para pakar peneliti di bidang teknologi yang bertujuan untuk memanjakan manusia satt ini. Dengan adanya android dijaman ini juga memotivasi penulis untuk mewujudkan pembuatan helm yang cerdas lagi.

\subsection{Saran}

Melihat dari batasan masalah dan penerapannya, penulis menyadari masih adanya kekurangan dalam penerapan helm cerdas ini, yaitu masih terbatasnya user/pengguana penerapan helm cerdas ini, lokasi harus terjangkau jaringan internet karena untuk dapat dilihat di google maps dan mengirim pesan harus melalui jaringan internet. Untuk itu penulis berharap adanya perluasan jaringan internet supaya penerapan helm cerdas dapat diterapkan dimana saja. Selain itu penulis berharap tidak hanya sampai disini saja penelitian mengenai pemanfaatan teknologi untuk bidang transportasi dilakukan.

\section{Daftar Pustaka}

1) Junaidi, A. (2015). Internet Of Things, Sejarah, Teknologi Dan Penerapannya: Review. Jurnal Ilmiah Teknologi Informasi Terapan. Vol. I, No. 3

2) Burange, A. W., \& Misalkar, H. D. (2015). Review of Internet of Things in Development of Smart Cities with Data Management \& Privacy.

3) S. Samsugi, Ardiansyah, Dyan Kastutara. (2018). Arduino Dan Modul Wifi Esp8266 Sebagai Media Kendali Jarak Jauh Dengan Antarmuka Berbasis Android. Jurnal TEKNOINFO, Vol. 12, No. 1

4) Agus Mulyanto, Yeni Agus Nurhuda, Imam Khoirurosid. (2017). SISTEM KENDALI LAMPU RUMAH MENGGUNAKAN SMARTPHONE ANDROID. Jurnal TEKNOINFO, Vol. 11, No. 2

5) Mentary Adisthi, Vinensia Meisclin Nanlohy, Tri Tjahjono. (2017). EVALUASI KECELAKAAN LALULINTAS SELAMA MUDIK LEBARAN MELALUI JALUR DARAT DI INDONESIA TAHUN $2015 D A N$ 2016. Jurnal Transportasi Vol. 17 No. 1 